\title{
Cognitive and Functional Outcome of Patients with Ischemic Stroke at Dr. Hasan Sadikin Hospital Bandung
}

\author{
Najmia Shabrina Nahrowi, ${ }^{1}$ Paulus Anam Ong, ${ }^{2}$ Achmad Adam ${ }^{3}$ \\ ${ }^{1}$ Faculty of Medicine Universitas Padjadjaran, Indonesia, ${ }^{2}$ Department of Neurology Faculty \\ of Medicine Universitas Padjadjaran/Dr. Hasan Sadikin General Hospital Bandung, Indonesia, \\ ${ }^{3}$ Department of Neurosurgery Faculty of Medicine Universitas Padjadjaran/ \\ Dr. Hasan Sadikin General Hospital Bandung, Indonesia
}

\begin{abstract}
Background: Stroke is the second leading cause of death and adult disability throughout the world in which the risk of cognitive impairment tripled after stroke. Approximately $30 \%$ of the patients experience residual disabilities and over half of patients remain physically dependent following a stroke. This study aimed to describe cognitive and functional outcome of patients with ischemic stroke at Dr. Hasan Sadikin Hospital Bandung.

Methods: This retrospective descriptive study used secondary data from medical records (JanuaryDecember 2013) of patients with ischemic stroke at Dr. Hasan Sadikin Hospital, Bandung, and was conducted from June-September 2017. Cognitive outcome was determined by the final score of the Indonesia version of MoCA (MoCA-INA), classified into impaired if the score was $<26$ and normal if the score was $>26$. Whereas functional outcome was determined by degradation of Barthel Index (BI), from complete dependence to independence. Data were analyzed, presented in the form of tables.

Results: Out of a total of 91 subjects consisting of 46 female (50.55\%) and 45 male (49.45\%), the result showed 55 subjects $(60.44 \%)$ had cognitive impairment with memory $(75.82 \%)$ as the highest prevalence of impaired cognitive domain. The functional outcome was 34 patients $(37.37 \%)$ had moderate to complete dependence whereas only 13 patients (14.29\%) were independent.

Conclusions: Cognitive impairment occurs in more than $75 \%$ ischemic stroke patients with memory as the most commonly impaired domain and more than one third of ischemic stroke patients still have moderate to complete dependence in activities of daily living (ADL).
\end{abstract}

Keywords: Cognitive outcome, functional outcome, ischemic

\section{Introduction}

According to WHO, stroke is a clinical syndrome consisting of rapidly developing clinical signs of focal (or global in case of coma) disturbance of cerebral function lasting more than 24 hours or leading to death with no apparent cause other than a vascular origin. ${ }^{1}$ Stroke is the second leading cause of death after ischemic heart disease. ${ }^{2}$ The results of the Basic Health Research 2013, (Riset Kesehatan Dasar, RISKESDAS) shows that stroke is the leading cause of death in Indonesia. The prevalence of stroke increases from 8.2 per 1000 (2007) to 12.1 per 1,000 (2013). ${ }^{3}$ The incidence of stroke tripled the risk of cognitive impairment and $30 \%$ of the patients experience residual disabilities, over half of patients remaining physically dependent following a stroke and approximately two-thirds having some form of neurological impairment at five years poststroke. ${ }^{2,4}$

The Montreal Cognitive Assessment (MoCA) is a screening tool used to detect mild cognitive impairment. MoCA has a maximum score of 30; a score less than 26 indicate the presence of cognitive impairment. MoCA could be used to detect the mild form of cognitive impairment despite normal result of the MiniMental State Examination (MMSE). MoCA has higher sensitivity than MMSE because MoCA evaluates the executive function, a cognition domain that often get impaired on stroke patients, moreover MoCA score could be adjusted with education level.5,6 The Barthel Index (BI), originally described in 1955 by Dr. Florence Mahoney and Dorothea Barthel, is a ten-item measure of activities of daily living

Correspondence: Najmia Shabrina Nahrowi, Faculty of Medicine, Universitas Padjadjaran, Jalan Raya BandungSumedang Km.21, Jatinangor, Sumedang, Indonesia, Email: najmiashabrina@gmail.com 
(ADL). In stroke medicine, BI is used in clinical practice to assess baseline abilities, to quantify functional change after rehabilitation and to inform discharge planning. ${ }^{7}$

Previous studies show a rather vast variation of cognitive and functional outcomes due to multiple factors. The aim of this study was to recognize the cognitive and functional outcomes of ischemic stroke patients in Bandung.

\section{Methods}

This was a retrospective descriptive study conducted from June to September 2017. The population in this study was medical records of ischemic stroke patients registered at Dr. Hasan Sadikin Hospital Bandung (period January-December 2013). The inclusion criteria specified in this study were ischemic stroke patients, had medical resume consisting of patient's demography (name, age, sex, education, occupation), risk factors (diabetes mellitus, hypertension, dyslipidemia and smoking) and a completely filled $\mathrm{BI}$ and MoCA-Indonesian version (MoCA-INA). The exclusion criteria in this study were the data found had an incomplete medical resume, the patient had aphasia, prestroke cognitive impairment, major psychiatric conditions and acute confusional state/delirium when going home.

Table 1 Basic Demographic and Clinical Data

\begin{tabular}{|c|c|c|}
\hline Variable & Frequency $(n=91)$ & Percentage (\%) \\
\hline \multicolumn{3}{|l|}{ Age (years) } \\
\hline $20-29$ & 1 & 1.10 \\
\hline $30-39$ & 3 & 3.30 \\
\hline $40-49$ & 20 & 21.98 \\
\hline $50-59$ & 35 & 38.46 \\
\hline $60-69$ & 22 & 24.18 \\
\hline$>70$ & 10 & 10.99 \\
\hline \multicolumn{3}{|l|}{ Gender } \\
\hline Male & 45 & 49.45 \\
\hline Female & 46 & 50.55 \\
\hline \multicolumn{3}{|l|}{ Education } \\
\hline Uneducated & 18 & 19.78 \\
\hline Elementary School & 37 & 40.66 \\
\hline Junior High School & 11 & 12.09 \\
\hline Senior High School & 18 & 19.78 \\
\hline College & 7 & 7.69 \\
\hline \multicolumn{3}{|l|}{ Occupation } \\
\hline Not Working & 47 & 51.65 \\
\hline Employee & 6 & 6.59 \\
\hline Entrepreneur & 15 & 16.48 \\
\hline Farmer/Fisherman/Labor & 16 & 17.58 \\
\hline Others & 7 & 7.69 \\
\hline \multicolumn{3}{|l|}{ Modifiable Risk Factor } \\
\hline Hypertension & 70 & 76.92 \\
\hline Dyslipidemia & 15 & 16.48 \\
\hline Smoking & 29 & 31.87 \\
\hline Diabetes Mellitus & 12 & 13.19 \\
\hline
\end{tabular}


Table 2 Prevalence of Cognitive Impairment of Patient with Ischemic Stroke

\begin{tabular}{lcc}
\hline \multicolumn{1}{c}{ Cognitive Impairment } & Frequency $(\mathbf{n = 9 1 )}$ & Percentage (\%) \\
\hline Normal (MoCA-INA $>$ 26) & 36 & 39.56 \\
Impaired (MoCA-INA <26) & 55 & 60.44 \\
Visuospatial/Executive & 52 & 57.14 \\
Attention & 59 & 64.84 \\
Language & 53 & 58.24 \\
Abstraction & 48 & 52.75 \\
Delayed Recall & 69 & 75.82 \\
Orientation & 40 & 43.96 \\
\hline
\end{tabular}

Note: MoCA-INA, Montreal Cognitive Assessment Indonesian Version

Cognitive impairment was determined if the MoCA-INA score was less than 26, whereas functional outcome was determined by the degradation of Barthel Index. This study had been approved previously by the Health Research Ethic Committee of the Faculty of Medicine, Universitas Padjadjaran with registration number 41/UN6.C.10/PN/2017.

All collected data were then analyzed using computer. Furthermore, the results of data analysis were displayed in the form of tables and graphs.

\section{Results}

The results of the subject sampling showed, out of 185 ischemic stroke patients, 94 patients did not meet the inclusion criteria due to aphasia and incomplete MoCA-INA and Barthel Index. Thus, the total subjects of the study were 91 patients.

From the total of 91 samples, the incidence of ischemic stroke was more common in the age group 50-59 (38.46\%) and least common in the younger age group. The incidence rate was slightly higher in women $(50.55 \%)$ than in men $(49.45 \%)$ by a very close difference.
Ischemic stroke was most common in patients with elementary school education $(40.66 \%)$ and least common in college level patients $(7.69 \%)$. Not working patients were more likely to have ischemic stroke compared to working patients; with the highest incidence of $51.65 \%$ in the not working group and the lowest incidence of $6.59 \%$ in patients who worked as employee. The most common risk factor in patients with ischemic stroke was hypertension with $76.92 \%$, and the least common was diabetes mellitus with $13.19 \%$ (Table 1).

Furthermore, out of the total of 91 poststroke patients, 55 patients $(60.44 \%)$ had cognitive impairment whereas 36 patients (39.56\%) had normal cognitive function. The highest prevalence of impaired cognitive domain was delayed recall (75.82\%), followed by attention (64.84\%), language (58.24\%), visuospatial / executive (57.14\%), abstraction $(52.57 \%)$, and the lowest was orientation (43.96\%) (Table 2).

Moreover, i was found that the prevalence of subjects with moderate to complete dependence was $37.37 \%$, and only $14.29 \%$ was with independent subjects (Table 3).

Table 3 Prevalence of Functional Outcome Using Barthel Index Score

\begin{tabular}{|c|c|c|c|}
\hline Score & Interpretation & $\mathbf{n}$ & $\%$ \\
\hline $0-20$ & Complete Dependency & 13 & 14.29 \\
\hline $25-40$ & Severe Dependency & 8 & 8.79 \\
\hline $45-55$ & Moderate Dependency & 13 & 14.29 \\
\hline $60-95$ & Mild Dependency & 44 & 48.35 \\
\hline 100 & Independent & 13 & 14.29 \\
\hline Total & & 91 & 100 \\
\hline
\end{tabular}




\section{Discussion}

The basic demographic and clinical data in this study included age, sex, education level, occupation and modifiable risk factors such as hypertension, diabetes mellitus, dyslipidemia, and smoking. Ischemic stroke was found most commonly in the 50-59 age group. This is consistent with a number of recent epidemiological studies that remarkably show the incidence of ischemic stroke at younger ages has been increasing since 1980s to present. ${ }^{8}$ The incidence of stroke increases with aging, however there is a shift of stroke trend in younger patients. A prospective population based study conducted for 16 years reveals an increase of stroke incidence in those who are aged 45 to 59 years. It could be due to the rise in classical cardiovascular risk factors such as diabetes mellitus, obesity and high cholesterol level. ${ }^{9}$ Ischemic stroke is only slightly more common in female than male $(50.55 \%$ vs. $49.45 \%)$. Another retrospective hospitalbased study by Farhoudi et al. ${ }^{10}$ in Iran reveals a similar result in male $(50.6 \%)$ and female (49.4\%). Moreover, the Basic Health Research (Riskesdas) 2013 result shows that stroke prevalence is similar in male and female. ${ }^{3}$

The prevalence of ischemic stroke is highest in patients with elementary school education and is less compared to those with higher education level, with the highest incidence of $40.66 \%$ at elementary school level and the lowest incidence of $7.69 \%$ at college level. This is probably due to the low knowledge of healthy lifestyle, namely maintaining food and exercise regularly. ${ }^{11}$ This study showed that the prevalence of ischemic stroke was greater in those who did not work with a percentage of $51.65 \%$. This result is due to the influence of socioeconomic, educational and knowledge levels. ${ }^{12}$ The risk factor of subjects with hypertension as the highest prevalence is $76.92 \%$, likewise to another epidemiologic study. The second highest was smoking with $31.87 \%$. The association between smoking and ischemic stroke is well known and can be attributed to large-vessel atherosclerosis with stenosis. ${ }^{10}$ It was followed by dyslipidemia with $16.48 \%$. This occurs probably due to increased intake of high carbohydrate and high fat diet that in decade can affect the high serum triglyceride. ${ }^{12}$ The lowest prevalence was diabetes mellitus, as much as $13.19 \%$.

Moreover, in this study, the overall prevalence of Post-Stroke Cognitive Impairment (PSCI) was $60.44 \%$. In other studies of PSCI in Indonesia, a hospital-based, cross sectional study by Hanas et al. ${ }^{13}$ reveals the incidence of PSCI is $92.68 \%$.

In comparison, the prevalence of PSCI in previously reported studies in a number of countries varies from $17 \%$ to $92 \%$. This vast variation can be associated mainly to diversities in study site-areas, time since stroke onset, stroke type, assessment methods and diagnostic criteria. ${ }^{14}$

At three months post-stroke, approximately $60 \%$ of patients were estimated to suffer from major or residual deficits in at least one cognitive domain. The most commonly impaired cognitive domain in this study was memory (75.82\%), followed by attention (64.84\%), language $(58.24 \%)$, visuospatial/ executive (57.14\%), abstraction (52.57\%), and the lowest was orientation $(43.96 \%)$. This is consistent with the result of a review conducted by Mohd Zulkifly et al. ${ }^{15}$ which states, the most common cognitive impairments among stroke survivors are memory, orientation, language and attention, executive dysfunction (initiation inhibition, mental flexibility) and aphasia. Infarctions are bound by vascular territory, thus damage is hardly limited to regions purely sub serving memory formation. ${ }^{16}$ Depending on adjacent regions involved, strokes causing memory problems commonly co-occur with language and visuospatial/executive deficits. ${ }^{16}$ However, individuals with stroke often have other comorbidities, so the manifestation of cognitive symptoms after stroke is not always as expected from the location of the lesion or even the area of hypoperfusion. Demographic (age and sex) and medical factors (fever, hyperglycaemia, seizures, previous history of stroke, cognitive difficulties before the onset of stroke, and medications) appeared to have some influences to which cognitive deficits after stroke are present. ${ }^{17}$

In this study, the prevalence of subjects with moderate to complete dependency was $37.37 \%$, distinctively only $14.29 \%$ of subjects were independent. This result is consistent with that of the American Heart Association, ${ }^{18}$ which states that $14 \%$ of stroke survivors will achieve full recovery in their basic ADLs, between $25-50 \%$ require at least some assistance, and approximately half of them experience severe long-term dependency. The independence of ADLs is affected by various factors, stroke patients at older age, recurrent strokes, hemorrhagic stroke, dependent financial resources and risk of malnourishment have poorer ADL. ${ }^{19}$

The limitation of this study is data are obtained from the medical resume of patients 
whose completeness is lower than that of the primary medical records. In addition, for a further study medical resume improvements are required.

As a conclusion, more than $75 \%$ of the ischemic stroke patients experience cognitive impairment and the most commonly impaired domain is memory. Approximately one third of the ischemic stroke patients experience moderate to complete dependency in activities of daily living while only less than $15 \%$ patients are independent.

\section{References}

1. Sacco RL, Kasner SE, Broderick JP, Caplan LR, Connors JJ, Culebras A, et al. An updated definition of stroke for the 21st Century. Stroke. 2013;44(7):2064-89.

2. Mellon L, Brewer L, Hall P, Horgan F, Williams D, Hickey A. Cognitive impairment six months after ischaemic stroke: a profile from the ASPIRE-S study. BMC Neurology. 2015;15(1):31.

3. Kementrian Kesehatan Republik Indonesia. Riset Kesehatan Dasar (Riskesdas) 2013. Jakarta: Badan Penelitian dan Pengembangan Kesehatan Kementerian Kesehatan; 2013.

4. Danovska M, Peychinska D. Post-stroke cognitive impairment - phenomenology and prognostic factors. J of IMAB. 2012;18(3):290-7.

5. Stolwyk RJ, O’Neill MH, McKay AJD, Wong DK. Are cognitive screening tools sensitive and specific enough for use after stroke? a systematic literature review. Stroke. 2014;45(10):3129-34.

6. Teasell R, Hussein N. Rehabilitation of cognitive impairment post stroke. In: Teasell R, Hussein N, Viana R, Madady M, Donaldson S, McClure A, et al. Stroke rehabilitation clinician handbook. London: Department of Physical Medicine and Rehabilitation Western University; 2014.

7. Duffy L, Gajree S, Langhorne P, Stott DJ, Quinn TJ. Reliability (Inter-rater Agreement) of the Barthel Index for assessment of stroke survivors. Stroke. 2013;44(2):462-8.

8. Putaala J. Ischemic stroke in the young: current perspectives on incidence, risk factors, and cardiovascular prognosis. European Stroke Journal. 2016;1(1):2840.

9. Wang Y, Rudd AG, Wolfe CD. Age and ethnic disparities in incidence of stroke over time. Stroke. 2013;44(12):3298-304.

10. Farhoudi M, Mehrvar K, Sadeghi-Bazargani H, Hashemilar M, Seyedi-Vafaee M, SadeghiHokmabad E, et al. Stroke subtypes, risk factors and mortality rate in northwest of Iran. Iran J Neurol. 2017;16(3):112-7.

11. Adams HP, Jr., Biller J. Classification of subtypes of ischemic stroke: history of the trial of org 10172 in acute stroke treatment classification. Stroke. 2015;46(5):e114-7.

12. Romero JR, Morris J, Pikula A. Review: Stroke prevention: modifying risk factors. Ther Adv Cardiovasc Dis. 2008;2(4):287303.

13. Hanas M, Lestari E, Asni EK. Gambaran Fungsi Kognitif pada Pasien Pasca Stroke di Poliklinik Saraf RSUD Arifin Achmad Provinsi Riau. Jurnal Online Mahasiswa (JOM) Fakultas Kedokteran Universitas Riau. 2016;3(1):1-12.

14. Qu Y, Zhuo L, Li N, Hu Y, Chen W, Zhou Y, et al. Prevalence of post-stroke cognitive impairment in China: a communitybased, cross-sectional study. PLOS ONE. 2015;10(4):e0122864.

15. Mohd Zulkifly MF, Ghazali SE, Che Din N, Singh DKA, Subramaniam P. A review of risk Factors for Cognitive Impairment in Stroke Survivors. The Scientific World Journal. 2016;2016(1):1-16.

16. Godefroy 0 . The behavioral and cognitive neurology of stroke. 2nd. Cambrigde, UK: Cambridge University Press; 2014.

17. Gottesman RF, Hillis AE. Predictors and assessment of cognitive dysfunction resulting from ischaemic stroke. Lancet Neurol. 2010;9(9):895-905.

18. Kwakkel G, Veerbeek JM, Harmelingvan der Wel BC, van Wegen E, Kollen BJ. Diagnostic accuracy of the Barthel Index for measuring activities of daily living outcome after ischemic hemispheric stroke. Stroke. 2011;42(2):342-6.

19. Pei L, Zang X-Y, Wang Y, Chai Q-W, Wang J-Y, Sun C-Y, et al. Factors associated with activities of daily living among the disabled elders with stroke. International Journal of Nursing Sciences. 2016;3(1):29-34. 